\title{
Acquired Hyperthyroidism
}

National Cancer Institute

\section{Source}

National Cancer Institute. Acquired Hyperthyroidism. NCI Thesaurus. Code C129635.

Hyperthyroidism, the cause of which is not present from birth. 